\title{
Assessment of the prophylactic activity and pharmacokinetic profile of oral tafenoquine compared to primaquine for inhibition of liver stage malaria infections
}

\author{
Qigui Lï, Michael O’Neil, Lisa Xie, Diana Caridha, Qiang Zeng, Jing Zhang, Brandon Pybus, Mark Hickman
} and Victor Melendez

\begin{abstract}
Background: As anti-malarial drug resistance escalates, new safe and effective medications are necessary to prevent and treat malaria infections. The US Army is developing tafenoquine (TQ), an analogue of primaquine (PQ), which is expected to be more effective in preventing malaria in deployed military personnel.

Methods: To compare the prophylactic efficacy of TQ and PQ, a transgenic Plasmodium berghei parasite expressing the bioluminescent reporter protein luciferase was utilized to visualize and quantify parasite development in C57BL/6 albino mice treated with $\mathrm{PQ}$ and $\mathrm{TQ}$ in single or multiple regimens using a real-time in vivo imaging system (IVIS). As an additional endpoint, blood stage parasitaemia was monitored by flow cytometry. Comparative pharmacokinetic (PK) and liver distribution studies of oral and intravenous PQ and TQ were also performed.

Results: Mice treated orally with three doses of TQ at $5 \mathrm{mg} / \mathrm{kg}$ three doses of PQ at $25 \mathrm{mg} / \mathrm{kg}$ demonstrated no bioluminescence liver signal and no blood stage parasitaemia was observed suggesting both drugs showed 100\% causal activity at the doses tested. Single dose oral treatment with $5 \mathrm{mg}$ TQ or $25 \mathrm{mg}$ of PQ, however, yielded different results as only TQ treatment resulted in causal prophylaxis in P. berghei sporozoite-infected mice. TQ is highly effective for causal prophylaxis in mice at a minimal curative single oral dose of $5 \mathrm{mg} / \mathrm{kg}$, which is a five-fold improvement in potency versus PQ. PK studies of the two drugs administered orally to mice showed that the absolute bioavailability of oral TQ was 3.5-fold higher than PQ, and the AUC of oral TQ was 94-fold higher than oral $P Q$. The elimination half-life of oral TQ in mice was 28 times longer than $P Q$, and the liver tissue distribution of TQ revealed an AUC that was 188-fold higher than PQ.
\end{abstract}

Conclusions: The increased drug exposure levels and longer exposure time of oral TQ in the plasma and livers of mice highlight the lead quality attributes that explain the much improved efficacy of TQ when compared to PQ.

Keywords: Prophylactic activity, Pharmacokinetic profile, Tafenoquine, Primaquine, Liver stage, Malaria infections, In vivo image system

\footnotetext{
* Correspondence: qigui.li.civ@mail.mil

Division of Experimental Therapeutics, Walter Reed Army Institute of

Research, 503 Robert Grant Avenue, Silver Spring, MD 20910, USA
} 


\section{Background}

The 8-aminoquinoline (8-AQ) anti-malarials, such as primaquine (PQ), have attracted much interest as chemotherapeutic and prophylactic agents against the liver stages of Plasmodium vivax and Plasmodium falciparum malaria parasites (Figure 1). The 8-AQs are the only known class of drugs with activity against both $P$. vivax hypnozoites and P. falciparum gametocytes. The World Health Organization recommends PQ in combination with chloroquine for the radical cure of $P$. vivax malaria, although limited compliance with the 14-day dosing regimen is known to impact effectiveness [1]. The clinical value of this class is compromised by the toxic side effects, however, which include methemoglobinaemia and haemolytic anaemia in patients with deficiency in glucose-6-phosphate dehydrogenase (G6PD) activity [2].

Tafenoquine (TQ) is a 5-phenoxyl derivative of PQ with a long elimination half-life, which is under development by the US Army and GlaxoSmithKline Pharmaceuticals for treatment of relapsing $P$. vivax malaria and malaria prophylaxis. TQ has been shown to have activity against both the blood and liver stages of malaria. In vitro and in vivo animal models have shown that TQ is more potent and less toxic than PQ [3]. TQ has advantages as a chemoprophylactic agent, which is needed to address the problems of patient drug compliance, tolerance, and efficacy in both semi-immune and nonimmune populations [4]. Phase I, II, and III clinical studies have shown that TQ is a safe, well-tolerated, and highly effective oral chemoprophylactic agent for the treatment of Plasmodium infections [5-7].

Given its long half-life of approximately 14 days, TQ has the potential to address problems with patient compliance during radical cure treatment of $P$. vivax, as
Phase II studies of TQ treatment of vivax infections have shown that 1-3 days of treatment is effective to prevent $P$. vivax relapse when used alone or in combination with other anti-malarials $[7,8]$. In addition to effectiveness against hypnozoites, TQ also has been shown to have anti-gametocyte activity and long-acting blood stage activity against multidrug resistant strains [5]. These are valuable lead quality attributes that make TQ a potentially important agent for P. falciparum eradication [9]. Early animal studies have demonstrated that TQ had greater activity than PQ against the hypnozoite stages of Plasmodium cynomolgi and had equivalent efficacy against Plasmodium knowlesi liver stage parasites in rhesus monkeys [2]. Other studies in rhesus monkeys have shown that TQ is also more effective against the bloodstage asexual parasites of P. cynomolgi, P. knowlesi and Plasmodium fragile than PQ [10-12].

In vitro data have shown that TQ has from 4 to 100 times higher blood schizonticidal activity against cultured parasites of Plasmodium berghei, Plasmodium yoelii, and P. falciparum, including multi-drug-resistant strains [13-16]. TQ has been shown to inhibit sporozoite development in Anopheles stephensi mosquitoes that fed on $P$. berghei infected mice [17]. Further study in rodent malaria liver stage by real time in vivo imaging system (IVIS) have shown that the prophylactic activity of TQ is 3-4 times higher than PQ against liver stage malaria parasites administered subcutaneously [18]. The only study of the liver stage effects of TQ on a human Plasmodium species, P. vivax, demonstrated significant sporontocidal activity of TQ against Anopheles dirus mosquitoes infected with $P$. vivax [19]. An in vivo imaging of luciferase-expressing parasites was used to compare the liver stage activity of TQ versus PQ in rodents<smiles>COc1cc(NC(C)C(C)N)c2ncccc2c1</smiles>

Primaquine<smiles>COc1cc(C)c2c(Oc3cccc(C(F)(F)F)c3)c(OC)cc(NC(C)C)c2n1</smiles>

Tafenoquine

Figure 1 Chemical structures of primaquine and tafenoquine. 
infected with $P$. berghei sporozoites. In vivo imaging of luciferase-expressing $P$. berghei parasites is conducted by using a sensitive camera to examine the luminescence emitted from anesthetized infected mice injected IP with luciferin. In vivo imaging has been successfully used to study P. berghei [18,20-25] and P. yoelii [26-28], which are commonly used to study the efficacy of agents against liver-stage. The authors' laboratory acquired a luciferase-expressing $P$. berghei parasite from the MR4 repository, and this organism has used successfully to examine the time course of $P$. berghei infection in rodents, and the organ-specific activity associated with malaria drugs that exhibit true liver stage activity.

As previously discussed, TQ has been shown to be highly effective for both radical cure of relapsing malaria and causal prophylaxis. Relatively few mechanism studies have systematically characterized the sporontocidal property of oral TQ, however, compared to the current standard of care, oral PQ. Literature citations have relied on a single pharmacokinetic (PK) advantage of TQ's longer half-life as a mechanism to explain enhanced liver stage activity. In this study, the liver stage activity of TQ and PQ in $P$. berghei infected mice was examined kinetically with a focus on prophylaxis of $P$. berghei sporozoites infected mice during the malaria liver-stage by using a modified real time imaging method. PK assays were used to provide a systematic PK profile for both drugs in mice to include 1) oral absolute bioavailability of TQ and PQ; 2) drug distribution in liver tissue, which is the target organ of both drugs; 3) drug elimination half-lives in liver and plasma; 4) drug concentration ratios of liver to plasma; and 5) total drug clearance.

\section{Methods}

\section{Study drugs}

TQ and PQ were formulated as a salt, but they were dosed in this study per the base compound weights. The bulk drug of TQ used for the test was synthesized for WRAIR by Ash Stevens, Inc. (Detroit, MI) and had a purity of $>99.8 \%$ by LC-MS/MS measurement.

\section{Sporozoites, inoculation and viability check}

Luciferase-expressing P. berghei ANKA sporozoites were obtained from laboratory-reared female An. stephensi mosquitoes from the Department of Mosquito Biology, WRAIR. The mosquitoes were maintained at $18^{\circ} \mathrm{C}$ for 17 to 22 days after feeding on P. berghei malaria infected Swiss ICR mice. Salivary glands were extracted from malaria-infected mosquitoes and kept on ice in RPMI medium with $1 \%$ mouse serum. Sporozoites will be recovered by the method of Ozaki [29], and quantitated using a haemocytometer. Sporozoites isolated from the same batch of mosquitoes will be inoculated into C57BL/6 albino mice on the same day to control for biological variability in sporozoite preparations. Each C57BL/6 mouse will be inoculated intravenously in the tail vein with approximately 50,000 sporozoites suspended in $0.1 \mathrm{~mL}$ volume on day 0 . To ensure that inoculated sporozoites are viable following the isolation procedure, they will be stained with a vital dye containing fluorescein diacetate $(50 \mathrm{mg} / \mathrm{mL}$ in acetone) and ethidium bromide $(20 \mu \mathrm{g} / \mathrm{mL}$ in phosphate-buffered saline; Sigma Chemical Co., St. Louis, Mo.) and counted in a haemocytometer. The viability of sporozoites ranged from 87 to $100 \%$.

\section{Animals}

Male 6-week-old C57BL/6 albino mice (NCI-Frederick, $\mathrm{MD})$ were used for malaria liver-stage in vivo imaging assays, and male 7-week-old ICR mice (Charles River Lab, MA) were used for the PK evaluations. On arrival, the animals were acclimated for seven days in quarantine. The animals were housed in a cage maintained in a room with a temperature range of $64-79^{\circ} \mathrm{F}, 34-68 \%$ relative humidity and a 12-h light/dark cycles. Food and water were provided ad libitum during quarantine and throughout the study. The animals were fed a standard rodent maintenance diet. All animal studies were performed under IACUC approved protocols. These protocols detail the experimental procedures and designs as well as number of animals were used. All animal use, care, and handling were performed in accordance with the current "Guide for the Care and Use of Laboratory Animals" (8 ${ }^{\text {th }}$ Edition, NIH, 2011) Science Education \& Strategic Communications Walter Reed Army Institute of Research.

\section{Test agent administration and sampling}

Novel and control anti-malarials were administered orally on days $-1,0$, and 1 with respect to sporozoite inoculation. At 24, 48, and 72 hours post sporozoite infection, all inoculated mice were tested using the IVIS Spectrum instrument (Perkin Elmer, Hanover, MD). Additionally, blood stage infections were measured by flow cytometry. Positive and negative controls were used for the IVIS calibration in each test.

Causal prophylactic effects and delay in onset of parasitaemia in animals treated with TQ and PQ (Figure 1) were assessed in these experiments, which included a positive control, 4-methyl-PQ. All dosing was conducted based on the body weight at the time of preparation of the dosing solution. Both PQ and TQ were dissolved in distilled water and administered intragastrically with concentrations ranging from $1.25-25 \mathrm{mg} / \mathrm{kg}$ body weight. A once-a-day, three-consecutive-day treatment regimen ( $-1,0,1$ day) was used in all assessments, on the day before sporozoite challenge, the day of challenge, and the day after challenge. Each animal received 
$0.1-0.2 \mathrm{ml}$ of the oral solutions, delivered via an intragastric feeder (18-gauge) to the designated recipient. Stock solutions of test compounds were prepared fresh daily by grinding the needed amount of drug in cold $\left(4^{\circ} \mathrm{C}\right) 0.5 \%$ $(\mathrm{w} / \mathrm{v})$ hydroxyethyl cellulose and $0.2 \%$ (v/v) Tween-80 $(0.5 \%$ HECT) and diluting the resulting solution at variable concentrations. C57BL/6 albino mice were challenged intravenously with 50,000 luciferase-expressing $P$. berghei sporozoites extracted from the salivary glands of heavily infected $A n$. stephensi mosquitoes. In vivo imaging was performed at 24, 48, and 72 hours after infection. At day 5-30 after infection, the same mice were analysed for blood stage infection by determination of the course of parasitaemia of tail blood by flow cytometry using an FC500 flow cytometer (Beckman-Coulter Co. CA). Blood samples ( $3 \mu \mathrm{L}$ each) for parasitaemia determinations were collected on day 5 after inoculation and every other day thereafter until a pair of positive parasitaemia was demonstrated or for 30 days, then twice weekly for another 4 weeks if negative for parasites.

\section{In vivo image system (IVIS)}

In vivo imaging studies of bioluminescence activity from luciferase expressing $P$. berghei infected mice were performed using a Perkin Elmer IVIS Spectrum (Hanover, MD). Mice were evaluated at 24, 48, and 72 hours post sporozoite inoculation to determine liver- and blood-stage malaria infection. Mice received $150 \mathrm{mg} / \mathrm{kg}$ luciferin (Gold Biotechnology, St. Louis, MO) intraperitoneally in a volume not to exceed $150 \mu \mathrm{L}$. Three minutes post luciferin administration the mice were anesthetized with inhaled isoflurane. The mice were then positioned ventral side up in the IVIS on a $37^{\circ} \mathrm{C}$ platform. The mice continue to receive isoflurane through nose cone delivery. The camera exposure times utilized were 1 and 5 minutes for the 24, 48 , and 72 hour time points with f-stop $=1$ and large binning setting. Quantitative analysis of bioluminescence emitted from whole bodies or region of intensity (ROI) were determined by measuring the luminescence signal intensity in photons/second using the ROI settings of the Living Image 3.0 software. The ROI, which measurements were expressed in total flux of photons, was set to measure the abdominal area at the location of the liver from whole body imaging.

\section{Flow cytometry (FCM)}

At day 5-30 after infection, the same mice were analysed for blood stage infections by quantitation of malaria parasites by flow cytometry (FCM). All FCM analyses were carried out with a FC500 MPL flow cytometer (Beckman Coulter, Fullerton, CA), which conducts five-colour analysis from either single or dual laser excitation. Infected erythrocytes, uninfected erythrocytes, and leukocytes were gated on logarithmic forward/side dot plots. Cells were analysed at an average rate of 2,000-3,000 erythrocytes/s. Filters were placed before the green (FL-1) and red (FL-2) photomultiplier tubes (PMTs) such that the green PMT registered fluorescence emission between 520 and $555 \mathrm{~nm}$, and the red PMT measured emission greater than $580 \mathrm{~nm}$.

A drop of blood $(3 \mu \mathrm{L})$ from the mouse tail was collected directly into $0.3 \mathrm{ml}$ of $1 \%$ heparinized isotonic buffer (PBS saline). In this study, $1 \mathrm{ml} 0.04 \%$ of glutaraldehyde was used for fixation and the samples were then incubated at $4^{\circ} \mathrm{C}$ for 60 minutes. The cells were centrifuged at $450 \times \mathrm{g}$ for $5 \mathrm{~min}$. The supernatant was removed by aspiration, and the cells were re-suspended in $0.5 \mathrm{ml}$ PBS buffer supplemented with $0.25 \%(\mathrm{v} / \mathrm{v})$ Triton X-100 for 10 minute incubation at room temperature. After centrifugation, the permeabilized cells were re-suspended in $0.5 \mathrm{ml}$ of RNAse at $1 \mathrm{mg} / \mathrm{ml}$ concentrations and incubated for at least 2 hours at $37^{\circ} \mathrm{C}$ to ensure complete digestion of reticulocytes. Plasmodium berghei infection in mice results in anaemia which then results in reticulocytosis. Therefore, high RNAse concentrations for digesting large amounts of reticulocytes RNA were required for assessment of parasitaemia in this mouse model. YOYO-1 dye (from $1 \mathrm{mM}$ stock solution in DMSO, as supplied by the manufacturer) was diluted to $2500 \mathrm{ng} / \mathrm{mL}$ (100-fold) concentrations in PBS and $20 \mu \mathrm{L}$ of YOYO-1 solution at $2500 \mathrm{ng} / \mathrm{mL}$ was added to $0.5 \mathrm{~mL}$ of sample to a final dye concentration of $100 \mathrm{ng} / \mathrm{ml}$ of YOYO-1, which has been shown to be optimal to discriminate infected erythrocytes from the lowest $(0.01 \%)$ to the highest parasitaemia counts (74.0\%) [30,31].

\section{Pharmacokinetic (PK) studies}

PK studies were performed using both intravenous (IV) and intragastric (IG) administration. For each time point to be acquired, three male ICR mice per time-point, aged seven weeks, were dosed at either PQ or TQ at $5 \mathrm{mg} / \mathrm{kg}$ (IV) or $20 \mathrm{mg} / \mathrm{kg}$ (IG). Drug vehicle for IV studies was $0.9 \%$ saline solution, and the formulated drugs were administered in a volume of $100 \mu \mathrm{L} / 20 \mathrm{~g}$ of body weight. For IG dosing, the drug vehicle was $0.5 \% \mathrm{HECT}$, administered at $100 \mu \mathrm{L} / 20 \mathrm{~g}$. At each time point, plasma and liver samples were collected. Whole blood was collected by cardiac puncture. Blood samples were collected in lithium heparin tubes within $0 \mathrm{~h}$ (baseline) prior to drugs administration and at $0.5,1,2,4,8,24,48,96,168$, and $336 \mathrm{~h}$ after drug administration. Following the separation of appropriate aliquots, plasma was obtained from the whole blood via centrifugation. All liquid and tissue samples were immediately preserved on dry ice and lately stored at $-80^{\circ} \mathrm{C}$ until analytical work was performed.

\section{LC-MS/MS analysis}

Sample was prepared by adding twice the normal volume of acetonitrile containing indomethacin internal 
standard (IS). The samples were mixed for 1 minute, centrifugation for 5 minutes, and the supernatant was transferred to an autosampler injection vial prior to separation by LC/MS/MS. Standard curve and quality control (QC) samples were generated by spiking interference free mouse plasma samples with known amounts of PQ, TQ and IS. Standard curve, QC, and assay samples were prepared and then $40 \mu \mathrm{L}$ aliquots were injected into the $\mathrm{LC} /$ MS/MS system for chromatographic separation and subsequent mass spectrometric detection.

Blank liver homogenate was prepared by adding $5 \mathrm{~mL}$ of water for each gram of liver, then the mixture was homogenized using an ultra-sonication probe (VCX 750, Sonics \& Materials, Inc., Newtown, CT). Plasma and liver homogenate standard curves were prepared via serial dilutions from a high concentration value (generally $500 \mathrm{ng} / \mathrm{mL}$ ) through a series of 10-11 lower concentration values. The serial dilutions for analysis also included the preparation of 4-5 QC samples at a low range point and a high range point (generally $10 \mathrm{ng} / \mathrm{mL}$ and $100 \mathrm{ng} / \mathrm{mL}$, respectively). Once the standard curve dilutions were prepared, a $100 \mu \mathrm{L}$ aliquot was removed and extracted with $200 \mu \mathrm{L}$ acetonitrile. The extracted samples were centrifuged at 10,000 rpm for $10 \mathrm{~min}$ and the supernatant was removed for analysis by LC-MS/MS. Sample drug concentrations were first interpolated from the standard curve, then multiplied by a factor of 6 to account for the drug levels present in the liver prior to dilution with water for homogenization.

Chromatography was performed using a Surveyor pump (Thermo Scientific, Waltham, MA) with Waters XTerra MS C18 $50 \mathrm{~mm} \times 2.1 \mathrm{~mm}$ id, $3.5 \mu \mathrm{m}$ particle size columns (Waters Corp., Milford, MA). Mobile phase consisted of a water $/ 0.1 \%$ formic acid (Solvent A)/acetonitrile/0.1\% formic acid (Solvent B) gradient. The gradient began at $2 \% \mathrm{~B}$, rose to $98 \%$ B from $1 \mathrm{~min}$ to $3.5 \mathrm{~min}$, held steady for $2 \mathrm{~min}$, then returned immediately to its starting composition and allowed to equilibrate for $1.5 \mathrm{~min}$. Flow rate was $300 \mu \mathrm{L} / \mathrm{min}$. Samples were injected using an HTC PAL autosampler (LEAP Technologies, Carrboro, NC). Tandem mass spectrometry was performed using a TSQ Quantum AM (Thermo Scientific).

\section{PK parameter determination}

Drug concentrations were generated for each sample taken from animals dosed with both test drugs. A measured plasma and liver drug concentration $v s$. time curve was produced, in graphic and tabular form, for each subject on both linear/linear and $\log /$ linear scales, for the parent compound. Mean plasma drug concentration vs. time curves were also prepared separately. For the determination of initial approach to PK parameters of TQ and $\mathrm{PQ}$ in plasma and liver tissues after systemic application, a non-compartmental analysis was performed using Phoenix (version 6.1; Pharsight Corp., Mountain View, CA). Maximum plasma and liver concentration $\left(C_{\max }\right)$, and time to maximum concentration $\left(t_{\max }\right)$ of TQ and PQ were obtained from the plasma and liver drug concentration-time curves. The elimination half-life $\left(t_{1 / 2}\right)$ was calculated from In $2 / k_{\mathrm{el}}$, which is the elimination rate constant calculated from the log concentration-time plot. The area under the curve (AUC) and the area under the first moment curve (AUMC) were determined by the linear trapezoidal rule with extrapolation to infinity based on the concentration of the last time point divided by the terminal rate constant. Mean clearance rate $(\mathrm{CL})$ was determined by dividing the dose by the $\mathrm{AUC}_{\mathrm{inf}}$ for intravenous injection for plasma samples. Absolute bioavailability was calculated by taking the dose-corrected area under the curve (AUC) from non-intravenous dosing divided by the AUC derived from intravenous dosing. Mean residence time (MRT) was determined by dividing the area under the first moment curve (AUMC) by AUC. The volume of the central compartment $(\mathrm{Vz})$ and volume of the tissue compartment $(\mathrm{Vz} / \mathrm{F})$ were calculated as the product of CL and MRT.

\section{Data analysis}

A Perkin Elmer In Vivo Imaging System (IVIS) Spectrum was used to provide a quantitative evaluation at 24,48 , and 72 hours post sporozoite inoculation to determine compound activity against liver- and blood-stage parasites. In the in vivo imaging experiments, causal prophylaxis activity, sporontocidal activity, parasite clearance, causal cure, delays in patency, and time to recrudescence were calculated as described previously [31]. The minimum curative dose $\left(\mathrm{MCD}_{100}\right)$ in $100 \%$ animals was defined as the lowest dose, which cured all animals $(>5$ animals) in a group at any time during the first 30 days of the follow-up period. The data were generally found to fit a normal distribution. Means and standard deviations of photon measurement were calculated. Blood stage infection was defined as two positive blood samples by flow cytometry, taken daily apart. The negative blood samples were monitored until day 15 after inoculation. Coefficients of variation were calculated as a percentage by dividing the standard deviation by the mean value. Statistical analysis was conducted with Microsoft Excel software by using a Student $t$ test for dependent samples to compare the means of paired and unpaired samples between treatment groups.

\section{Results}

Real time in vivo imaging of liver-stage model in mice

Real time in vivo imaging to determine the timing and level of luminescence measured from luciferase expression of sporozoites development in the liver was described previously by Ploemen et al. [18] and Thiberge 
et al. [20]. The IVIS instrument was used to measure luciferase activity of infected sporozoites in liver cells. Five mice per group were treated with or without different doses of prophylactic drugs starting one day before infection, the day during infection with luciferasesporozoites, and the last dose at one day after infection. The test subjects were infected with 50,000 sporozoites by intravenous injection in the tail vein and the luminescence levels were determined 24, 48, and 72 hours post infection.

Mean luminescence values (photon counts) collected from liver location of untreated control mice were $2.07 \times 10^{6}$ photons/second $(\mathrm{CV}=47.5 \%)$ at 24 hours and $35.48 \times 10^{6}$ photons/second $(\mathrm{CV}=44.9 \%)$ at 48 hours. In the untreated control animals, there was a strong increase in bioluminescence signal at 48 hours, and the liver region of intensity (ROI) was increased 17.2-fold when compared to 24 hours subjects. The liver stage of $P$. berghei is 48 hours in duration, and no significant blood stage activity was not observed after the 48 hour liver stage was completed (Figure 2, right). At 72 hours, mean luminescence signals of $127.67 \times 10^{6}$ photons/second $(\mathrm{CV}=$ $65.3 \%$ ), could be detected only in the whole bodies of untreated mice, which was 3.6 times higher than the luminescence measured at 48 hours, suggesting that the majority of the increase in luminescence observed was produced by blood stage $P$. berghei parasites [18]. This is consistent with the known 48-hour duration of the liver stage of $P$. berghei malaria model where parasites invade erythrocytes after the rupture of liver schizonts 48 hours post inoculation.

\section{Prophylactic efficacy of $P Q$ and TQ after daily dosing for 3 days}

Analysis of the inhibition of in vivo liver stage development by PQ and TQ was assessed by measuring luminescence using a Perkin Elmer Spectrum In Vivo Imaging System (IVIS). Mice were treated with daily doses of PQ

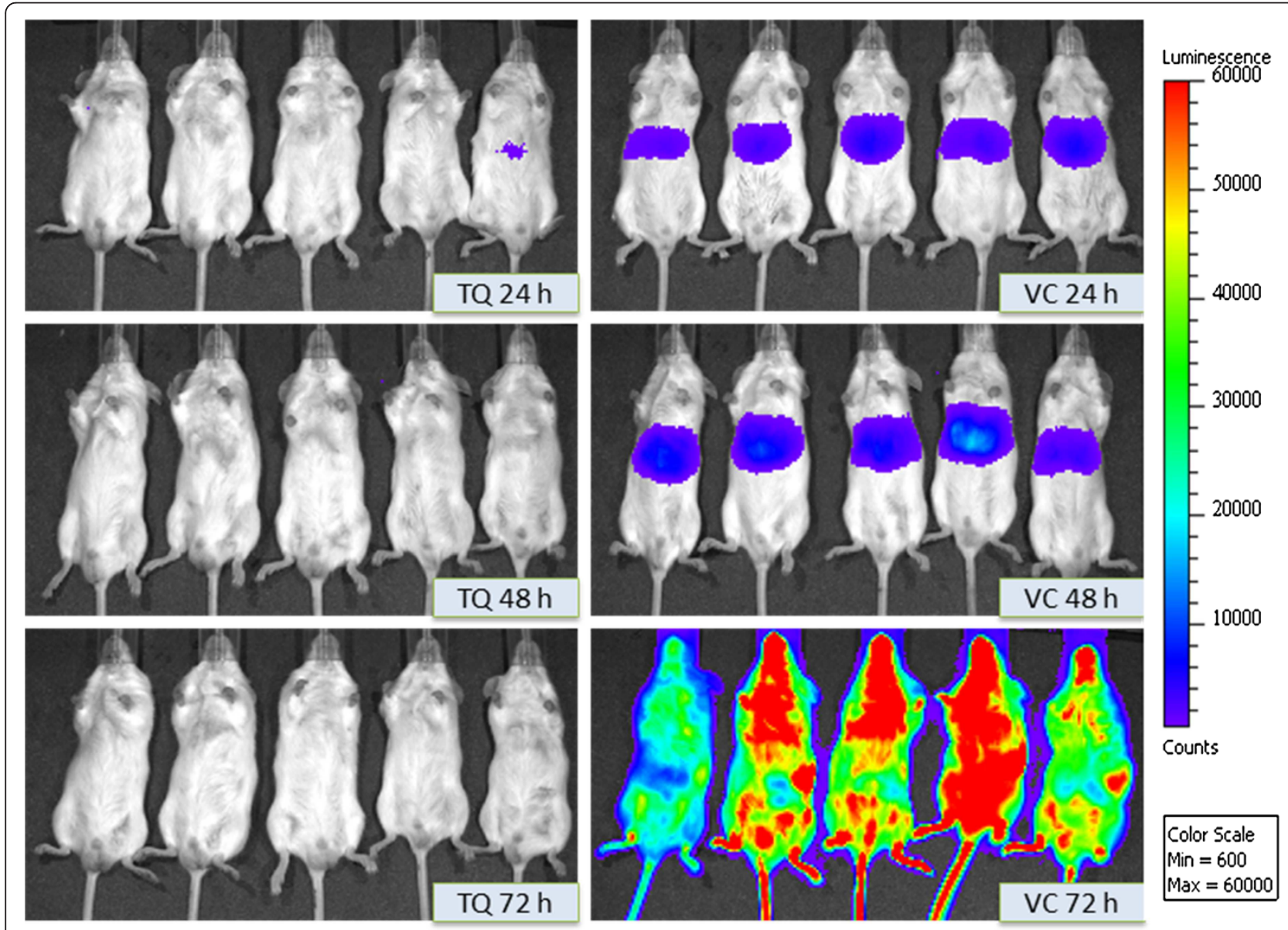

Figure 2 Representative in vivo images (IVIS) of luminescence shown in the livers of live C57BL/6 albino mice at different time points after injection of $5 \times 10^{4}$ sporozoites. Rainbow images show the relative levels of luminescence ranging from low (blue), to medium (green), to high (yellow/red). Luminescence levels (photons/sec) of livers in whole mice at 24, 48 and 72 hour time points following intragastric dosing daily for 3-consecutive-day on days -1, 0, 1, treated with tafenoquine (TQ) at a dose of $5 \mathrm{mg} / \mathrm{kg}$ (TQ, left) and vehicle control (VC, right) after sporozoite infection intravenously at day 0. Normally, P. berghei sporozoites reside in the mouse liver for $44-52$ hours post-infection $(n=4)$. 
at $5,10,15,20$, and $25 \mathrm{mg} / \mathrm{kg}$ body weight for 3 days and daily doses of TQ at $1.25,2.5,5$, and $10 \mathrm{mg} / \mathrm{kg}$ body weight for three consecutive days (Table 1, Figure 2, left).

In mice treated with $2.5 \mathrm{mg} / \mathrm{kg}$ body weight of TQ, 2 out of 5 mice showed a low level of luminescence ranging between $0.09 \times 10^{5}$ and $0.35 \times 10^{5}$ photons/second at 24-48 hours while the remaining 3 mice were negative. Two of these five mice developed a blood stage parasitaemia that was delayed by $2-4$ days compared to the control mice. In 5 of 10 animals treated with $10 \mathrm{mg} / \mathrm{kg}$ $\mathrm{PQ}$, a low level of luminescence was observed at 48 hours $\left(0.66 \times 10^{5}\right.$ photons $\left./ \mathrm{sec}\right)$ while the remaining 5 mice were negative. Five of these ten mice developed a blood stage parasitaemia that was delayed by $2-4$ days compared to the control mice. All mice treated with $5 \mathrm{mg} / \mathrm{kg}$ of TQ and $25 \mathrm{mg} / \mathrm{kg}$ of PQ were luminescence negative during the observation period from 24 to 48 hours after infection, and none of these animals developed blood stage infection, suggesting that TQ is 5 times more potent for causal prophylaxis as PQ in this rodent malaria model. The complete inhibition of liver stage development by PQ at doses of $25 \mathrm{mg} / \mathrm{kg}$ body weight and higher and by TQ at doses of $5 \mathrm{mg} / \mathrm{kg}$ body weight and higher are in agreement with the inhibitory doses reported in the literature $[12-15,18]$.

\section{Prophylactic efficacy of single doses of PQ and TQ}

Mice treated with single oral doses of TQ at $5 \mathrm{mg} / \mathrm{kg}$ one day prior to infection showed causal prophylaxis results similar to those obtained through multiple doses of TQ at lower concentrations. A detectable luminescence signal in the liver was observed in mice treated with $5 \mathrm{mg} / \mathrm{kg}$ of TQ 24 and 48 hours after infection, but no blood stage parasitaemia was noted up to 30 days post infection suggesting that the suppressive effect of TQ against liver stage parasite growth and curative activity in the blood stage was due to a single oral dose of TQ (Table 1). In the group treated with a single oral dose of PQ at $25 \mathrm{mg} / \mathrm{kg}$, high levels of luminescence and no suppression of signal were observed in the livers of mice after 24 hours suggesting incomplete inhibition of parasite growth (Table 1). In addition, analysis of these mice 5-30 days after infection showed severe parasitaemia in peripheral blood, suggesting that the single dose failure of PQ may be due to its short half-life.

\section{PK and bioavailability of intravenous and orally dosed PQ or TQ in mice}

The individual computer fitted plasma concentrationtime curves following single intragastric administration of PQ in mice are shown in Figure 3. The PK parameter estimates in plasma derived from animals dosed at $5 \mathrm{mg} / \mathrm{kg}$ PQ intravenously and $20 \mathrm{mg} / \mathrm{kg}$ intragastrically are summarized in Table 2. The mean $C_{\max }$ and $\mathrm{AUC}_{\mathrm{inf}}$ of PQ was $1.21 \mu \mathrm{g} / \mathrm{ml}$ and $1.20 \mu \mathrm{g} \cdot \mathrm{h} / \mathrm{ml}$, respectively, following single dose IV administration. The mean elimination half-life of intravenous PQ was 0.63 hours and the total clearance rate was $4.19 \mathrm{liter} / \mathrm{h} / \mathrm{kg}$.

Oral PQ showed very rapid absorption and reached a plasma peak concentration $\left(\mathrm{T}_{\max }\right)$ at 0.50 hours. The mean $\mathrm{C}_{\max }$ and $\mathrm{AUC}_{\text {inf }}$ of $\mathrm{PQ}$ was $0.53 \mu \mathrm{g} / \mathrm{ml}$ and $1.31 \mu \mathrm{g} \cdot \mathrm{h} / \mathrm{ml}$, respectively, following a single dose orally administered. The mean elimination half-life of oral PQ was shown to be 1.84 hours and the total clearance rate was calculated to be 57.94 liter $/ \mathrm{h} / \mathrm{kg}$. The mean absolute bioavailability of oral PQ was calculated to be $28.32 \%$, and this calculation was also based on the data derived from intravenous dosing.

The PK parameters assessed in animals after doses of $5 \mathrm{mg} / \mathrm{kg}$ TQ intravenously and $20 \mathrm{mg} / \mathrm{kg}$ intragastrically are summarized in Table 2. The mean $\mathrm{C}_{\max }$ and $\mathrm{AUC}_{\text {inf }}$ of TQ was shown to be $0.66 \mu \mathrm{g} / \mathrm{ml}$ and $30.14 \mu \mathrm{g} \cdot \mathrm{h} / \mathrm{ml}$, respectively, following IV administration. The mean elimination half-life of IV TQ was 66.28 hours and the total clearance rate was 0.17 liter $/ \mathrm{h} / \mathrm{kg}$. TQ was shown to be absorbed very slowly with a $\mathrm{T}_{\max }$ of 11.33 hours. The results demonstrated that the mean $\mathrm{C}_{\max }$ and $\mathrm{AUC}_{\text {inf }}$ of TQ was $2.04 \mu \mathrm{g} / \mathrm{ml}$ and $139.18 \mu \mathrm{g} \cdot \mathrm{h} / \mathrm{ml}$, respectively, following oral administration. The mean elimination half-life of TQ was 50.87 hours and the total clearance rate was $0.15 \mathrm{liter} / \mathrm{h} / \mathrm{kg}$. The mean absolute bioavailability of oral TQ was calculated to be $100.77 \%$ in mice, and this calculation was also derived from the data derived from intravenous dosing.

In comparison to the oral PK plasma parameters shown, oral TQ has an absorption rate that is 22.7-fold slower than PQ in mice. The $\mathrm{C}_{\max }$ and $\mathrm{AUC}_{\text {inf }}$ of oral TQ were approximately 4-fold and 94-fold, respectively, higher than that of oral PQ. The elimination half-life of oral TQ was shown to be approximately 28 -fold longer and the elimination clearance was shown to be 370-fold slower than oral $\mathrm{PQ}$. The mean absolute bioavailability of oral TQ was 3.5-fold greater than oral PQ.

\section{Liver distribution of intravenous and oral $P Q$ or $T Q$ in mice}

In this study, the parasite drug targets are inside hepatocytes and, therefore, the PK profile of PQ and TQ in the liver tissue is important. The liver tissue distribution of PQ and TQ was analysed, and the PK parameter estimates in the livers of mice dosed with PQ intravenously at $5 \mathrm{mg} / \mathrm{kg}$ and intragastrically with $\mathrm{PQ}$ at a dose of $20 \mathrm{mg} / \mathrm{kg}$ are summarized in Table 2. The mean $\mathrm{C}_{\max }$ and $\mathrm{AUC}_{\text {inf }}$ of PQ was $3.99 \mu \mathrm{g} / \mathrm{g}$ and $6.14 \mu \mathrm{g} \cdot \mathrm{h} / \mathrm{g}$, respectively, following a single IV administration of $\mathrm{PQ}$. The ratio of the liver AUC to the plasma AUC in animals dosed with PQ intravenously was 3.91. The mean elimination half-life of PQ in the liver was 1.32 hours 
Table 1 The causal prophylactic activities of tafenoquine (TQ) and primaquine (PQ) by using real time in vivo image system (IVIS) following single dose (-1 or 0 day after inoculation) or daily oral administrations for 3 days multiple doses $(-1,0$, and 1 day after infection) against challenge with 50,000 sporozoites of the ANKA strain of $P$. berghei intravenously in male C57BL/6 albino mice with positive and negative controls ( $n=5-20$ each)

\begin{tabular}{|c|c|c|c|c|c|c|c|c|c|c|c|c|}
\hline \multirow{2}{*}{$\begin{array}{l}\text { Test } \\
\text { agents }\end{array}$} & \multirow{2}{*}{$\begin{array}{l}\text { Dose } \\
(\mathrm{mg} / \mathrm{kg})\end{array}$} & \multirow{2}{*}{$\begin{array}{l}\text { Oral } \\
\text { dose }\end{array}$} & \multirow{2}{*}{$\begin{array}{l}\text { Date of } \\
\text { dosing }\end{array}$} & \multicolumn{3}{|c|}{ Suppression rate (\%) IVIS ${ }^{*}$} & \multirow{2}{*}{$\begin{array}{l}\text { Blood } \\
\text { Infection } \\
\text { by FCM* }\end{array}$} & \multicolumn{3}{|c|}{ Number of C57BL/albino mice } & \multirow{2}{*}{$\begin{array}{c}\text { Delay in patency } \\
\text { (days after onset in controls) }\end{array}$} & \multirow[b]{2}{*}{ Effects } \\
\hline & & & & $24 \mathrm{~h}$ & $48 \mathrm{~h}$ & $72 \mathrm{~h}$ & & Challenged & $\begin{array}{l}\text { Protected } \\
\text { completely }\end{array}$ & $\begin{array}{c}\text { Causal } \\
\text { prophylaxis }\end{array}$ & & \\
\hline \multirow[t]{6}{*}{ Tafenoquine } & 10 & 3 days & $-1,0,1$ & 100 & 100 & 100 & $0 / 5$ & 5 & 5 & $5 / 5$ & - & Full CP \\
\hline & 5 & 3 days & $-1,0,1$ & 90.4 & 100 & 100 & $0 / 13$ & 13 & 13 & $13 / 13$ & - & Full CP \\
\hline & 2.5 & 3 days & $-1,0,1$ & 100 & 100 & 100 & $2 / 5$ & 5 & 3 & $3 / 5$ & - & Partial CP \\
\hline & 1.25 & 3 days & $-1,0,1$ & 84.7 & 92.3 & 98.9 & $4 / 5$ & 5 & 1 & $1 / 5$ & $2,4,4,7$ & Suppression \\
\hline & 5 & Single & -1 & 68.7 & 98.6 & 100 & $0 / 10$ & 10 & 10 & $10 / 10$ & - & Full CP \\
\hline & 5 & Single & 0 & 66.0 & 91.1 & 98.5 & $4 / 5$ & 5 & 1 & $1 / 5$ & $4,2,4,9$ & Partial CP \\
\hline \multirow[t]{7}{*}{ Primaquine } & 25 & 3 days & $-1,0,1$ & 100 & 100 & 100 & 0/10 & 10 & 10 & $10 / 10$ & - & Full CP \\
\hline & 20 & 3 days & $-1,0,1$ & 100 & 100 & 100 & $1 / 10$ & 10 & 9 & $9 / 10$ & 6 & Partial CP \\
\hline & 15 & 3 days & $-1,0,1$ & 100 & 100 & 100 & $4 / 20$ & 20 & 16 & $16 / 20$ & $2,2,2,1$ & Partial CP \\
\hline & 10 & 3 days & $-1,0,1$ & 100 & 97.6 & 100 & $5 / 10$ & 10 & 5 & $5 / 10$ & $2,4,2,2,4$ & Partial CP \\
\hline & 5 & 3 days & $-1,0,1$ & 82.4 & 77.5 & 89.4 & $5 / 5$ & 5 & 0 & $0 / 5$ & 2,2 & Suppression \\
\hline & 25 & Single & -1 & 45.7 & 0 & 0 & $5 / 5$ & 5 & 0 & $0 / 5$ & - & Suppression \\
\hline & 25 & Single & 0 & 11.2 & 0 & 0 & $5 / 5$ & 5 & 0 & $0 / 5$ & - & Suppression \\
\hline
\end{tabular}

"The infection was determined by recording the onset of IVIS for liver stage and parasitaemia for blood stage by using a flow cytometry system (FCM). $C P=$ causal prophylaxis. 

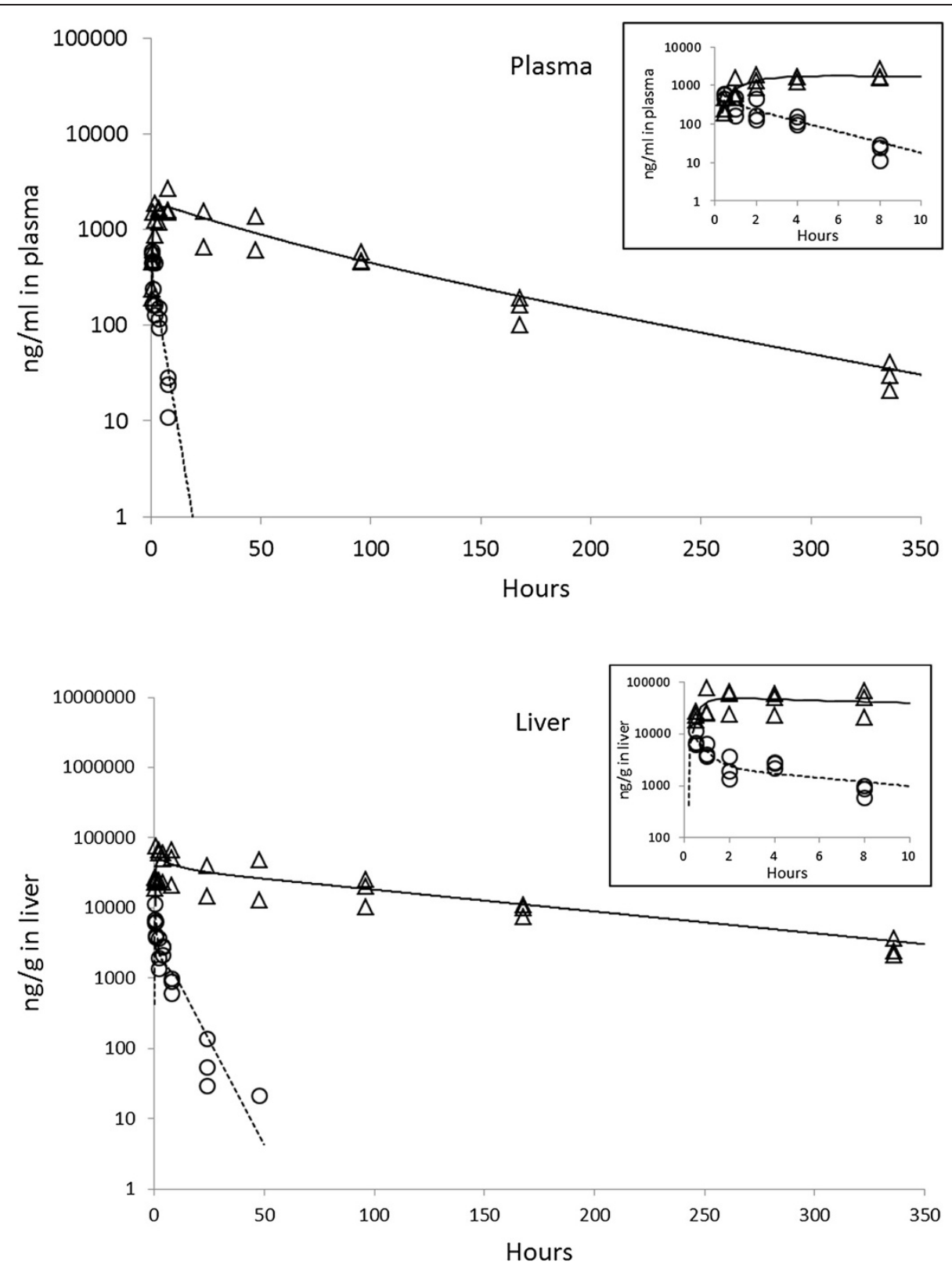

Figure 3 Individual plasma concentration-time profiles of tafenoquine (TQ, triangle markers) and primaquine (PQ, circle markers) measured by LC/MS/MS and computer fitted curves for TQ (solid line) and PQ (dashed line) at single intragastric dosage of $20 \mathrm{mg} / \mathrm{kg}$ in mouse plasma (top) and liver (bottom) $(n=3)$.

following IV injection. In the orally dosed PQ groups, the PK parameters derived showed a mean $C_{\max }$ and $\mathrm{AUC}_{\text {inf }}$ of $8.15 \mu \mathrm{g} / \mathrm{g}$ and $27.67 \mu \mathrm{g} \cdot \mathrm{h} / \mathrm{g}$, respectively, following a single oral dose of $\mathrm{PQ}$. The ratio of the liver AUC to the plasma AUC in animals dosed with PQ orally was 22.26 . The mean elimination half-life of PQ in liver was shown to be 4.28 hours following oral dosing.

Following TQ administration, the PK parameters derived showed a mean $\mathrm{C}_{\max }$ and $\mathrm{AUC}_{\text {inf }}$ of $44.76 \mu \mathrm{g} / \mathrm{g}$ and
$2544.96 \mu \mathrm{g} \cdot \mathrm{h} / \mathrm{g}$, respectively, following a single IV administration of TQ. The ratio of the liver AUC to the plasma AUC in animals dosed with TQ intravenously was 87.24. The mean elimination half-life of TQ in the liver was shown to be 70.02 hours following IV injection. After oral administration of TQ, the PK parameters derived showed a mean $\mathrm{C}_{\max }$ and $\mathrm{AUC}_{\text {inf }}$ of $56.90 \mu \mathrm{g} / \mathrm{g}$ and $5391.86 \mu \mathrm{g} \cdot \mathrm{h} / \mathrm{g}$, respectively, following single oral administration of TQ. The ratio of the liver AUC to the 
Table 2 Pharmacokinetic comparison of tafenoquine (TQ) and primaquine (PQ) in plasma and liver tissue following single intravenous at dose of $5 \mathrm{mg} / \mathrm{kg}$ and intragastric at dose of $20 \mathrm{mg} / \mathrm{kg}$ administrations in male mice $(\mathrm{n}=3)$

\begin{tabular}{|c|c|c|c|c|}
\hline \multirow{2}{*}{ PK parameters } & \multicolumn{2}{|c|}{ Tafenoquine (TQ) } & \multicolumn{2}{|c|}{ Primaquine (PQ) } \\
\hline & Plasma & Liver & Plasma & Liver \\
\hline \multicolumn{5}{|l|}{ Intravenous (5 mg/kg) } \\
\hline$C_{\max }(\mu \mathrm{g} / \mathrm{mL}$ or $\mathrm{g})$ & $0.66 \pm 0.13$ & $44.76 \pm 29.95$ & $1.21 \pm 0.21$ & $3.99 \pm 0.53$ \\
\hline $\mathrm{T}_{\max }$ (hours) & $1.36 \pm 1.11$ & $3.69 \pm 2.29$ & $0.08 \pm 0.0$ & $0.39 \pm 0.53$ \\
\hline$A \cup C_{\text {last }}(\mu \mathrm{g} \cdot \mathrm{h} / \mathrm{mL}$ or $\mathrm{g})$ & $29.63 \pm 6.74$ & $2493.82 \pm 1361.10$ & $1.20 \pm 0.13$ & $6.06 \pm 1.39$ \\
\hline$A \cup C_{\text {infininty }}(\mu \mathrm{g} \cdot h / \mathrm{mL}$ or $\mathrm{g})$ & $30.14 \pm 6.65$ & $2544.96 \pm 1348.03$ & $1.26 \pm 0.14$ & $6.14 \pm 1.38$ \\
\hline $\mathrm{t}_{1 / 2}$ elimination $(\mathrm{h})$ & $66.28 \pm 10.32$ & $70.02 \pm 4.35$ & $0.63 \pm 0.08$ & $1.32 \pm 0.06$ \\
\hline Vz (liter/kg) & $16.76 \pm 6.44$ & - & $3.85 \pm 0.71$ & - \\
\hline Cl (liter/h/kg) & $0.17 \pm 0.04$ & - & $4.19 \pm 0.42$ & - \\
\hline MRT (h) & $55.92 \pm 3.86$ & $66.11 \pm 19.19$ & $0.68 \pm 0.02$ & $1.27 \pm 0.11$ \\
\hline $\mathrm{AUC}_{\text {inf }}$ ratio (liver/plasma) & - & $87.24 \pm 44.29$ & - & $3.91 \pm 0.54$ \\
\hline \multicolumn{5}{|l|}{ Intragastric (20 mg/kg) } \\
\hline$C_{\max }(\mu \mathrm{g} / \mathrm{mL})$ & $2.04 \pm 0.59$ & $56.90 \pm 26.09$ & $0.53 \pm 0.07$ & $8.15 \pm 0.29$ \\
\hline$T_{\max }$ (hours) & $11.33 \pm 5.37$ & $1.17 \pm 0.76$ & $0.50 \pm 0.0$ & $0.50 \pm 0.0$ \\
\hline$A \cup C_{\text {last }}(\mu \mathrm{g} \cdot \mathrm{h} / \mathrm{mL})$ & $137.91 \pm 24.38$ & $5140.52 \pm 1794.60$ & $1.26 \pm 0.40$ & $27.45 \pm 1.84$ \\
\hline$A \cup C_{\text {infininty }}(\mu \mathrm{g} \cdot \mathrm{h} / \mathrm{mL})$ & $139.18 \pm 24.92$ & $5391.86 \pm 1898.51$ & $1.31 \pm 0.41$ & $27.67 \pm 1.75$ \\
\hline $\mathrm{t}_{1 / 2}$ elimination (h) & $50.87 \pm 4.23$ & $75.48 \pm 12.06$ & $1.84 \pm 0.45$ & $4.28 \pm 1.30$ \\
\hline Vz (liter/kg) & $10.60 \pm 1.22$ & - & $154.66 \pm 61.83$ & - \\
\hline Cl (liter/h/kg) & $0.15 \pm 0.03$ & - & $57.94 \pm 20.52$ & - \\
\hline MRT (h) & $62.08 \pm 2.30$ & $88.67 \pm 12.98$ & $2.28 \pm 0.10$ & $4.49 \pm 0.25$ \\
\hline$A \cup C_{\text {inf }}$ ratio (liver/plasma) & - & $48.91 \pm 22.67$ & - & $22.26 \pm 6.73$ \\
\hline Absolute bioavailability (\%) & $100.77 \pm 37.49$ & & $28.32 \pm 6.93$ & \\
\hline
\end{tabular}

$V z=$ Volume of distribution based on the terminal phase; $M R T=$ mean residence time, $D=$ Day.

plasma AUC in animals dosed orally with TQ was 48.91. The mean elimination half-life of TQ in liver was shown to be 75.48 hours following oral dosing.

In comparison to the liver distribution of oral $\mathrm{PQ}$, the $\mathrm{C}_{\max }$ and $\mathrm{AUC}_{\text {inf }}$ of orally dosed TQ were approximate 7-fold and 195-fold, respectively, much higher than that of PQ in liver tissue. The elimination half-life of oral TQ was estimated to be 17.6-fold longer than the elimination half-life of oral PQ in the liver.

\section{Discussion}

The screening and identification of agents that inhibit Plasmodium development in the liver is considerably more complex when compared to the very simple process of screening small molecules for inhibitory activity against blood-stage parasites. Quantitative analysis of liver stage development in small laboratory animals, in vivo, is hampered by the low levels of parasite infection as well as the complicated, time consuming and expensive traditional methods required to monitor parasite development, such as RT-PCR, RNA hybridization or direct counting of liver stages parasites. In vivo imaging is a technique that captures light emitted by the reaction of luciferase and its substrate luciferin, and this technique has been successfully used to study $P$. berghei $[18,20-25]$ and $P$. yoelii [26-28] liver stage infections, which were commonly used to study the efficacy of agents against liver-stage Plasmodium parasites. The addition of flow cytometric monitoring of blood stage parasites using the YOYO-1 intercalating dye $[30,31]$ provides a means of completely monitoring all aspects of the parasite life cycle in a rodent, from sporozoite infection to development of mature blood stage parasites.

To determine the timing and level of luminescence during $P$. berghei sporozoite development in the livers of infected rodents, groups of mice $(n=5)$ were infected intravenously with different numbers of sporozoites ranging from $5 \times 10^{3}$ to $1 \times 10^{5}$. Luciferase activity in the animals was visualized by whole body imaging using the IVIS Spectrum imaging system at 24, 48 and 72 hours after infection. In control, uninfected mice, luminescence values ranged between $1 \times 10^{2}$ and $1 \times 10^{3}$ photons/second. In 
mice infected with higher doses of sporozoites $\left(5 \times 10^{4}\right.$ and $1 \times 10^{5}$ sporozoites), all mice showed luminescence levels significant above background at 24 hours with luminescence activity of $2.1 \times 10^{6}$ and $5.3 \times 10^{6}$ photons $/ \mathrm{sec}-$ ond, respectively. Mice infected with $2.5 \times 10^{4}$ or fewer sporozoites showed a signal above background in only a few animals at 24 hours. In all infected mice there was a strong increase ( $6-17$ fold) in bioluminescence signal at 48 hours. Therefore, $5 \times 10^{4}$ sporozoites is the minimum sporozoite infectious burden required to induce luminescence levels above background in 100\% of the C57BL/6 albino mice tested. After 48 hours, luminescence signals could be detected in the whole body of infected animals, resulting from parasites that had invaded erythrocytes after the rupture of the liver schizonts. Based on these observations, a window of luminescence intensities between 24 and 48 hours was determined in subsequent experiments in mice infected with a constant number of $5 \times 10^{4}$ $P$. berghei sporozoites to test for liver-stage inhibition of drugs.

In vivo assessment of drug efficacy against liver stage Plasmodium parasites through in vivo imaging offers clear advantages over standard methods of RT-PCR analysis of dissected livers or through analysis of the dynamics of blood stage infections examined subsequent to liver-stage infection. In vivo imaging is simple and rapid and allows, within the same animal, measurement of both the specific inhibition of liver stage development by a small molecule and subsequent effects on blood stage parasites. In vivo imaging analysis does not require sacrificing experimental animals and thereby reduces the number of animals required for experimentation since multiple measurements can be made in the same animal over time. Furthermore, in vivo imaging also has the advantage that it minimizes the biological variation within the study $[24,28]$ as the in vivo analysis of PQ and TQ liver stage efficacy was performed with mice that were infected by intravenous injection of sporozoites. All the control mice in these experiments (i.e. infections in the absence of drug) injected intravenously with sporozoites showed strong luminescence signals at 24 and 48 hours after infection. Complete inhibition of signal in animals treated with PQ and TQ was observed at intragastric doses of $25 \mathrm{mg} / \mathrm{kg}$ and $5 \mathrm{mg} / \mathrm{kg}$, respectively, which correspond to liver-stage inhibitory concentrations reported in the literature for primaquine and tafenoquine treated subcutaneously with drug [18]. In conclusion, quantitative analysis of liver stage development by real-time imaging should greatly aid the development of drugs that act against the liver stages of Plasmodium parasites.

PQ and TQ themself are generally believed unlikely to be the clinically active form of the drug, because they have similar multiple pathways and are extensively metabolized and less active than some of its metabolites or derivatives in in vitro models [16,32]. Determination of metabolic pathways in vivo that lead to efficacy is difficult, because there is no in vitro model of hypnozoites within liver cells with which to evaluate efficacy. Therefore, currently, the liver-stage efficacy was likely relating to the PK concentrations of the parent drug of PQ and TQ. The absorption rate $\left(\mathrm{T}_{\max }\right)$ of 11.33 hours observed in animals treated with TQ suggests a slow absorption, which implies a prolonged period of absorption in the gut. Dissolution studies of TQ in simulated gastric fluid demonstrate complete dissolution within 30 minutes [33]. Thus, the long apparent absorption phase may be due to a distal GI absorption site combined with slow clearance of TQ as $T_{\max }$ is a function of both absorption and elimination rates. PQ is well absorbed from the gastrointestinal tract with peak plasma levels attained within 5 minutes in mice. TQ was found to be slowly but extensively metabolized [33]. TQ has been shown to be eliminated via biliary excretion with enterohepatic recirculation, but it is not eliminated in the urine. PQ is similarly extensively and rapidly metabolized with less than $1 \%$ of the dose excreted as unchanged drug in the urine [33]. In this study, the clearance (CL) of TQ was only $0.15 \mathrm{~L} / \mathrm{hours} / \mathrm{kg}$ ( $3 \%$ of the hepatic blood flow), while PQ has a much more rapid clearance of $57.94 \mathrm{~L} /$ hours $/ \mathrm{kg}$.

TQ has a 3.5-fold higher bioavailability was observed following oral administration than oral PQ. Also, TQ has a half-life that is more than 28 times longer was noted than PQ. Figure 3 illustrates the effect of this difference in half-lives between these two 8-aminoquinolines. A single $20 \mathrm{mg} / \mathrm{kg}$ dose of TQ results in easily quantifiable concentrations for more than two weeks. However, a single $20 \mathrm{mg} / \mathrm{kg}$ dose of PQ results in no detectable concentrations within 1 day after dosing. Modeling of TQ, on the other hand, is best described by a two-compartment model. This kinetic difference results in more prolonged, high concentrations of TQ in the blood. These properties of TQ provide an advantage over PQ in that they may permit long-term dosing for prophylaxis and short-term or single dose therapy for terminal eradication or radical cure of $P$. vivax malaria, which will likely result in improved compliance and enhanced effectiveness.

In this study, TQ was found to be 5-fold more potent than PQ as a liver schizonticides. This may be explained in part by its full bioavailability, accumulation in the blood and hepatocytes, prolonged elimination, and its longer half-life, in addition to difference in intrinsic activity. $\mathrm{PQ}$, on the other hand, does not accumulate inside blood and liver cells [33]. The increased drug exposure levels and longer exposure time of oral TQ in the plasma and livers of mice highlight the reasons for its enhanced anti-malarial activity. 


\section{Competing interests}

The authors declare that they have no competing interests.

\section{Authors' contributions}

$\mathrm{QL}$ and $\mathrm{MO}$ conceived of the study. $\mathrm{LX}, \mathrm{DC}, \mathrm{QZ}$, and JZ conducted the liver-stage efficacy study with IVIS. BP and VM conducted LC/MS/MS study. MH reviewed and edited this manuscript. All authors read and approved the final manuscript.

\section{Acknowledgements}

This study was supported by the United States Army Research and Materiel Command. Material has been reviewed by the Walter Reed Army Institute of Research. There is no objection to its presentation and/or publication. The opinions or assertions contained herein are the private views of the author and are not to be construed as official, or as reflecting the views of the Department of the Army or the Department of Defense.

Received: 15 January 2014 Accepted: 2 April 2014

Published: 14 April 2014

\section{References}

1. WHO: Guidelines for the Treatment of Malaria. Geneva, Switzerland: World Health Organization; 2006. Available at: http://www.who.int/malaria/ publications/atoz/9789241547925/en/. Accessed April 2014.

2. Shiraki H, Kozar MP, Melendez V, Hudson TH, Ohrt C, Magill AJ, Lin AJ: Antimalarial activity of novel 5-aryl-8-aminoquinoline derivatives. J Med Chem 2011, 54:131-142.

3. Brueckner RP, Coster T, Wesche DL, Shmuklarsky M, Schuster BG: Prophylaxis of Plasmodium falciparum infection in a human challenge model with WR 238605, a new 8-aminoquinoline antimalarial. Antimicrob Agents Chemother 1998, 42:1293-1294.

4. Walsh DS, Wilairatana P, Tang DB, Heppner DG Jr, Brewer TG, Krudsood S, Silachamroon U, Phumratanaprapin W, Siriyanonda D, Looareesuwan S: Randomized trial of 3-dose regimens of tafenoquine (WR238605) versus low-dose primaquine for preventing Plasmodium vivax malaria relapse. Clin Infect Dis 2004, 39:1095-1103.

5. Hale BR, Owusu-Agyei S, Fryauff DJ, Koram KA, Adjuik M, Oduro AR, Prescott WR, Baird JK, Nkrumah F, Ritchie TL, Franke ED, Binka FN, Horton J, Hoffman SL: A randomized, double-blind, placebo-controlled, dose-ranging trial of tafenoquine for weekly prophylaxis against Plasmodium falciparum. Clin Infect Dis 2003, 36:541-549.

6. Shanks GD, Oloo AJ, Aleman GM, Ohrtt C, Klotz FW, Braitman D, Horton J, Brueckner R: A new primaquine analogue, tafenoquine (WR 238605), for prophylaxis against Plasmodium falciparum malaria. Clin Infect Dis 2001, 33:1968-1974.

7. Walsh DS, Eamsila C, Sasiprapha T, Sangkharomya S, Khaewsathien P, Supakalin $\mathrm{P}$, Tang DB, Jarasrumgsichol $\mathrm{P}$, Cherdchu C, Edstein MD, Rieckmann KH, Brewer TG: Efficacy of monthly tafenoquine for prophylaxis of Plasmodium vivax and multidrug-resistant $P$. falciparum malaria. J Infect Dis 2004, 190:1456-1463.

8. Walsh DS, Looareesuwan S, Wilairatana P, Heppner DG Jr, Tang DB, Brewer TG, Chokejindachai W, Viriyavejakul P, Kyle DE, Milhous WK, Schuster BG, Horton J, Braitman DJ, Brueckner RP: Randomized dose-ranging study of the safety and efficacy of WR 238605 (Tafenoquine) in the prevention of relapse of Plasmodium vivax malaria in Thailand. J Infect Dis 1999, 180:1282-1287.

9. Nasveld PE, Edstein MD, Reid M, Brennan L, Harris IE, Kitchener SJ, Leggat PA, Pickford P, Kerr C, Ohrt C, Prescott W, Tafenoquine Study Team: Randomized, double-blind study of the safety, tolerability, and efficacy of tafenoquine versus mefloquine for malaria prophylaxis in nonimmune subjects. Antimicrob Agents Chemother 2010, 54:792-798.

10. Nasveld P, Kitchener S, Edstein M, Rieckmann K: Comparison of tafenoquine (WR238605) and primaquine in the post-exposure (terminal) prophylaxis of vivax malaria in Australian Defence Force personnel. Trans R Soc Trop Med Hyg 2002, 96:683-684

11. Cooper RD, Milhous WK, Rieckmann KH: The efficacy of WR238605 against the blood stages of a chloroquine resistant strain of Plasmodium vivax. Trans R Soc Trop Med Hyg 1994, 88:691-692.

12. Queener SF, Dean RA, Bartlett MS, Milhous WK, Berman JD, Ellis WY, Smith JW: Efficacy of intermittent dosage of 8-aminoquinolines for therapy or prophylaxis of Pneumocystis pneumonia in rats. J Infect Dis 1992, 165:764-768.

13. Bartlett MS, Queener SF, Tidwell RR, Milhous WK, Berman JD, Ellis WY, Smith JW: 8-Aminoquinolines from Walter Reed Army Institute for Research for treatment and prophylaxis of Pneumocystis pneumonia in rat models. Antimicrob Agents Chemother 1991, 35:277-782.

14. Peters W, Robinson BL, Milhous WK: The chemotherapy of rodent malaria. LI. Studies on a new 8-aminoquinoline, WR 238,605. Ann Trop Med Parasitol 1993, 87:547-552.

15. Ramharter M, Noedl H, Thimasarn K, Wiedermann G, Wernsdorfer G, Wernsdorfer $\mathrm{WH}$ : In vitro activity of tafenoquine alone and in combination with artemisinin against Plasmodium falciparum. Am J Trop Med Hyg 2002, 67:39-43.

16. Crockett $M$, Kain KC: Tafenoquine: a promising new antimalarial agent. Expert Opin Investig Drugs 2007, 16:705-715.

17. Coleman RE, Clavin AM, Milhous WK: Gametocytocidal and sporontocidal activity of antimalarials against Plasmodium berghei ANKA in ICR Mice and Anopheles stephensi mosquitoes. Am J Trop Med Hyg 1992, 46:169-182.

18. Ploemen $\mathbb{H}$, Prudêncio $M$, Douradinha BG, Ramesar J, Fonager J, van Gemert GJ, Luty AJ, Hermsen CC, Sauerwein RW, Baptista FG, Mota MM, Waters AP, Que I, Lowik CW, Khan SM, Janse CJ, Franke-Fayard BM: Visualisation and quantitative analysis of the rodent malaria liver stage by real time imaging. PLoS One 2009, 4:e7881.

19. Ponsa N, Sattabongkot J, Kittayapong P, Eikarat N, Coleman RE: Transmission-blocking activity of tafenoquine (WR-238605) and artelinic acid against naturally circulating strains of Plasmodium vivax in Thailand. Am J Trop Med Hyg 2003, 69:542-547.

20. Thiberge S, Blazquez S, Baldacci P, Renaud O, Shorte S, Ménard R, Amino R: In vivo imaging of malaria parasites in the murine liver. Nat Protoc 2007, 2:1811-1818.

21. Ploemen I, Behet M, Nganou-Makamdop K, van Gemert GJ, Bijker E, Hermsen C, Sauerwein R: Evaluation of immunity against malaria using luciferase-expressing Plasmodium berghei parasites. Malar J 2011, 10:350

22. Meister S, Plouffe DM, Kuhen KL, Bonamy GM, Wu T, Barnes SW, Bopp SE, Borboa R, Bright AT, Che J, Cohen S, Dharia NV, Gagaring K, Gettayacamin M, Gordon P, Groessl T, Kato N, Lee MC, McNamara CW, Fidock DA, Nagle A, Nam TG, Richmond W, Roland J, Rottmann M, Zhou B, Froissard P, Glynne RJ, Mazier D, Sattabongkot J, et al: Imaging of Plasmodium liver stages to drive next-generation antimalarial drug discovery. Science 2011, 334:1372-1377.

23. Nganou-Makamdop K, Ploemen I, Behet M, Van Gemert GJ, Hermsen C, Roestenberg M, Sauerwein RW: Reduced Plasmodium berghei sporozoite liver load associates with low protective efficacy after intradermal immunization. Parasite Immunol 2012, 34:562-569.

24. Annoura T, Chevalley S, Janse CJ, Franke-Fayard B, Khan SM: Quantitative analysis of Plasmodium berghei liver stages by bioluminescence imaging. Methods Mol Biol 2013, 923:429-443.

25. Lacrue AN, Sáenz FE, Cross RM, Udenze KO, Monastyrskyi A, Stein S, Mutka TS, Manetsch R, Kyle DE: 4(1H)-Quinolones with liver stage activity against Plasmodium berghei. Antimicrob Agents Chemother 2013, 57:417-424.

26. Mwakingwe A, Ting LM, Hochman S, Chen J, Sinnis P, Kim K: Noninvasive real-time monitoring of liver-stage development of bioluminescent Plasmodium parasites. J Infect Dis 2009, 200:1470-1478.

27. Ploemen $\mathrm{H}$, Chakravarty S, van Gemert GJ, Annoura T, Khan SM, Janse CJ, Hermsen CC, Hoffman SL, Sauerwein RW: Plasmodium liver load following parenteral sporozoite administration in rodents. Vaccine 2013, 31:3410-3416

28. Miller JL, Murray S, Vaughan AM, Harupa A, Sack B, Baldwin M, Crispe IN, Kappe SH: Quantitative bioluminescent imaging of pre-erythrocytic malaria parasite infection using luciferase-expressing Plasmodium yoelii. PLoS One 2013, 8:e60820.

29. Ozaki LS, Gwadz RW, Godson GN: Simple centrifugation method for rapid separation of sporozoites from mosquitoes. J Parasitol 1984, 70:831-833.

30. Xie L, Li Q, Johnson J, Zhang J, Milhous W, Kyle D: Development and validation of flow cytometric measurement for parasitaemia using autofluorescence and YOYO-1 in rodent malaria. Parasitology 2007, 134:1151-1162.

31. Li Q, Gerena L, Xie L, Zhang J, Kyle D, Milhous W: Development and validation of flow cytometric measurement for parasitemia in cultures of P. falciparum vitally stained with YOYO-1. Cytometry A 2007, 71A:297-307. 
32. Bates $M B$, Meshnick SR, Sigler $\mathrm{Cl}$, Leland $\mathrm{P}$, Hollingdale MR: In vitro effects of primaquine and primaquine metabolites on exoerythrocytic stages of Plasmodium berghei. Am J Trop Med Hyg 1990, 42:532-537.

33. Brueckner RP, Lasseter KC, Lin ET, Schuster BG: First-time-in-humans safety and pharmacokinetics of WR 238605, a new antimalarial. Am J Trop Med Hyg 1998, 58:645-649.

doi:10.1186/1475-2875-13-141

Cite this article as: Li et al: Assessment of the prophylactic activity and pharmacokinetic profile of oral tafenoquine compared to primaquine

for inhibition of liver stage malaria infections. Malaria Journal 2014 13:141.

\section{Submit your next manuscript to BioMed Central and take full advantage of:}

- Convenient online submission

- Thorough peer review

- No space constraints or color figure charges

- Immediate publication on acceptance

- Inclusion in PubMed, CAS, Scopus and Google Scholar

- Research which is freely available for redistribution 